\title{
III Primary Language, Income and the Intensification of Anti-glycemic Medications in Managed Care: the (TRIAD) Study
}

\author{
O. Kenrik Duru, MD, $M S^{7}$, Dori Bilik, MBA ${ }^{2}$, Laura N. McEwen, PhD², Arleen F. Brown, MD, PhD', \\ Andrew J. Karter, $P h D^{3}$, J. David Curb, MD ${ }^{4}$, David G. Marrero, PhD ${ }^{5}$, Shou-En Lu, PhD ${ }^{6}$, \\ Michael Rodriguez, $\mathrm{MD}^{7}$, and Carol M. Mangione, $\mathrm{MD}, \mathrm{MSPH}^{7}$
}

'Division of General Internal Medicine/Health Services Research, David Geffen School of Medicine, University of California, Los Angeles, Los Angeles, CA, USA; ${ }^{2}$ Department of Internal Medicine, Division of Endocrinology and Metabolism, University of Michigan, Ann Arbor, MI, USA; ${ }^{3}$ The Division of Research, Kaiser Permanente, Oakland, CA, USA; ${ }^{4}$ Department of Geriatric Medicine, John A. Burns School of Medicine, University of Hawaii, Honolulu, HI, USA; ${ }^{5}$ Department of Medicine, Indiana University School of Medicine, Indianapolis, IN, USA; ${ }^{6}$ Department of Biostatistics, UMDNJ-School of Public Health, Piscataway, NJ, USA; ${ }^{2}$ Department of Family Medicine, University of California, Los Angeles, Los Angeles, CA, USA.

BACKGROUND: Patients who speak Spanish and/or have low socioeconomic status are at greater risk of suboptimal glycemic control. Inadequate intensification of anti-glycemic medications may partially explain this disparity.

OBJECTIVE: To examine the associations between primary language, income, and medication intensification.

DESIGN: Cohort study with 18-month follow-up.

PARTICIPANTS: One thousand nine hundred and thirtynine patients with Type 2 diabetes who were not using insulin enrolled in the Translating Research into Action for Diabetes Study (TRIAD), a study of diabetes care in managed care.

MEASUREMENTS: Using administrative pharmacy data, we compared the odds of medication intensification for patients with baseline Alc $\geq 8 \%$, by primary language and annual income. Covariates included age, sex, race/ethnicity, education, Charlson score, diabetes duration, baseline Alc, type of diabetes treatment, and health plan.

RESULTS: Overall, $42.4 \%$ of patients were taking intensified regimens at the time of follow-up. We found no difference in the odds of intensification for English speakers versus Spanish speakers. However, compared to patients with incomes $<\$ 15,000$, patients with incomes of $\$ 15,000-\$ 39,999$ (OR 1.43, 1.07-1.92), $\$ 40,000-\$ 74,999$ (OR 1.62, 1.16-2.26) or >\$75,000 (OR $2.22,1.53-3.24)$ had increased odds of intensification. This latter pattern did not differ statistically by race.

CONCLUSIONS: Low-income patients were less likely to receive medication intensification compared to higherincome patients, but primary language (Spanish vs. English) was not associated with differences in intensifi-

Electronic supplementary material The online version of this article (doi:10.1007/s11606-010-1588-2) contains supplementary material, which is available to authorized users.

Received November 12, 2009

Revised June 8, 2010

Accepted November 15, 2010

Published online December 21, 2010 cation in a managed care setting. Future studies are needed to explain the reduced rate of intensification among low income patients in managed care.

$\mathrm{J}$ Gen Intern Med 26(5):505-11

DOI: $10.1007 / \mathrm{s} 11606-010-1588-2$

( ) The Author(s) 2010. This article is published with open access at Springerlink.com

\footnotetext{
A lthough glycemic control among patients with Type 2 diabetes has improved over the last two decades, minorities continue to have elevated hemoglobin Alc (A1c) values compared to whites. ${ }^{1}$ Non-English speaking minorities are at even greater risk of poor control, as Spanish-speaking Latinos with Type 2 diabetes have higher Alc values than Englishspeakers. $^{2-4}$ Income has also been associated with glycemic control, as low-income patients typically have higher Alc values than higher-income patients. ${ }^{5}$ As a result of ongoing poor metabolic control, both Spanish-speaking and lowincome patients with diabetes have disproportionately higher rates of microvascular complications. ${ }^{6,7}$

Inadequate intensification of anti-glycemic diabetes medications, either because providers never attempt to intensify the medication regimen ("clinical inertia") ${ }^{8}$ or because patients are unwilling to accept a more intensive regimen, potentially explains suboptimal glycemic control. Low-income and/or Spanish-speaking patients may be less likely than higherincome and/or English-speaking patients to begin intensified regimens for a variety of reasons, including poor patientprovider communication, lack of patient trust in the provider and/or the medications, concern about potential side effects, fewer outpatient visits and therefore less frequent opportunities to intensify, or concern about the additional out-of-pocket cost of potential new medications. ${ }^{9-12}$

While different intensification rates might explain observed disparities in control, few published studies have examined the association between either primary language or income and the intensification of anti-glycemic medications. A recent paper from the Translating Research into Action for Diabetes (TRIAD) study found a small, non-significant difference in medication
} 
intensification by patient income. ${ }^{13}$ However, the analytic sample for this study was limited to patients who completed a two-year follow-up survey, and patients from the lowest education and income strata were disproportionately excluded.

For the current TRIAD analysis, we hypothesized that within a prospective cohort of managed care patients who were not taking insulin and had suboptimal control of their diabetes at baseline (A1c $\geq 8.0 \%$ ), Spanish-speakers would be less likely than English-speakers to be taking intensified anti-glycemic medication regimens at follow-up. We defined intensification as the addition of a new medication or an increase in the dose of an existing medication. We further hypothesized that compared to higher-income patients, low-income patients within this cohort would be less likely to be taking intensified antiglycemic medication regimens at follow-up.

\section{METHODS}

\section{Setting and Participants}

The TRIAD study is a multiethnic, multisite study of diabetes care in managed care. ${ }^{14}$ TRIAD investigators collected survey data, administrative data, and conducted medical record review among a prospective cohort of managed care patients with diabetes. The TRIAD cohort was enrolled between July 2000 and August 2001 and randomly selected from 10 health plans and 68 provider groups, which served approximately 180,000 patients. Between $5 \%$ and $10 \%$ of patients within each plan had diabetes. The TRIAD health plans are located in different geographic areas, and include significant numbers of Mexican Americans (from Texas and California) as well as Puerto Ricans and Latinos of Caribbean background (from New Jersey).

Eligibility criteria for inclusion in TRIAD included a provider diagnosis of diabetes, age of 18 years or older, continuous enrollment in a participating health plan for a minimum of 18 months, at least one health care claim in the previous 18 months, having received the majority of diabetes care through the health plan, and the ability to speak either English or Spanish. Nursing home residents, pregnant women, and persons unable to provide informed consent were excluded. The study protocol was reviewed and approved by Institutional Review Boards at all participating sites. For this particular analysis, we defined suboptimal control of diabetes as Alc $\geq$ $8.0 \%$ at baseline. However, some providers may have used a lower Alc threshold to trigger therapy intensification. Therefore in a sensitivity analysis, we redefined suboptimal control as $\mathrm{Alc} \geq 7.0 \%$ at baseline.

We contacted 13,086 potentially eligible patients to complete the baseline survey. Respondents completed either a computer-assisted telephone or written survey. The survey was completed by 11,927 patients (91\%). As we were unsuccessful in contacting some patients, we followed the Council of American Survey Research Organizations (CASRO) protocol, assuming that patients whom we could not contact or for whom we could not confirm eligibility had the same proportion of eligibility as those contacted. ${ }^{15}$ Under that assumption, the CASRO response rate for the baseline survey was $69 \%$.

For this analysis, we excluded patients with Type 1 diabetes ( $n=669$ ), defined as the subgroup less than 30 years of age who were taking insulin but no oral anti-glycemic agents (Fig. 1).

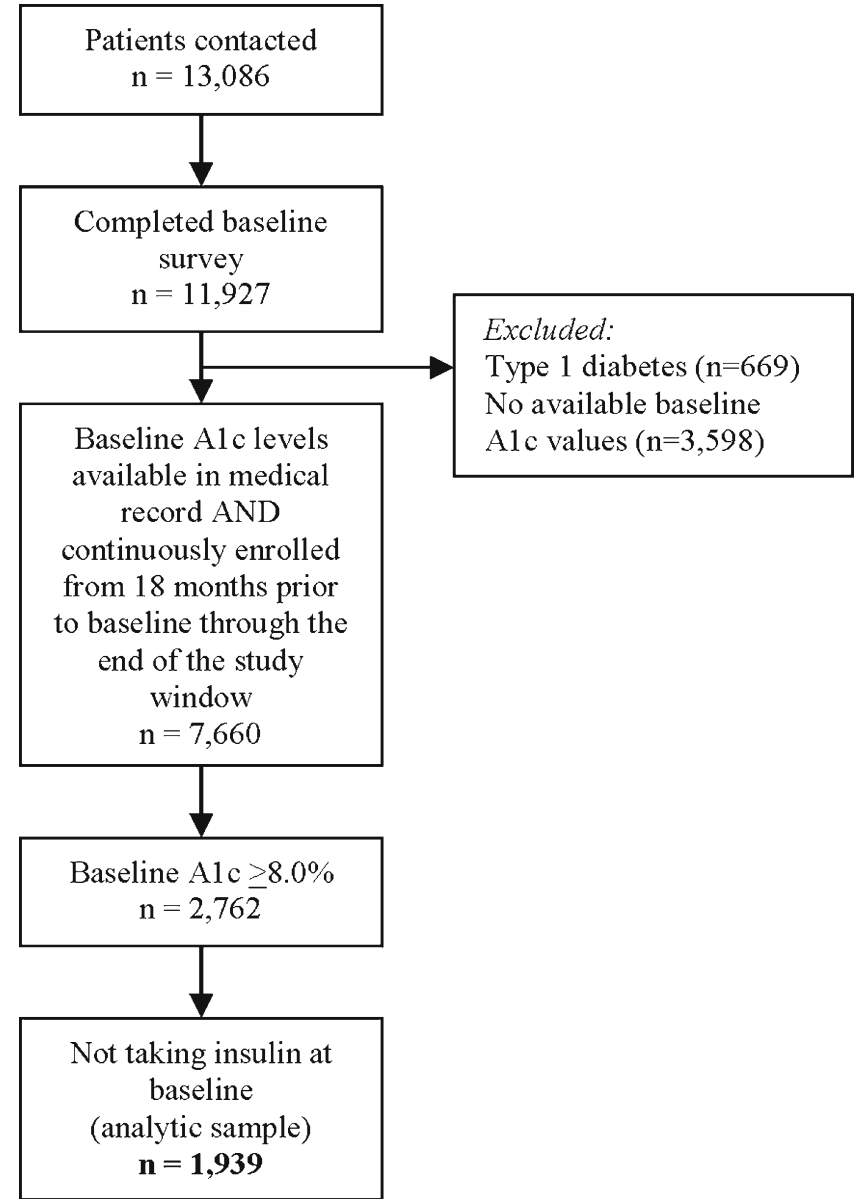

Figure 1. Derivation of analytic sample.

Alc levels from the medical record were available for 7,660 of the patients with Type 2 diabetes who completed surveys and were continuously enrolled for the 18 months prior to baseline and remained enrolled (allowing a gap of no more than 2 months) through the end of the administrative data window. The majority of these patients $(n=2,762)$ had Alc values $\geq 8.0 \%$ and were therefore classified as suboptimally controlled. As intensification of insulin among existing users is difficult to discern from pharmacy claims, we excluded patients already taking insulin, resulting in a final analytic sample of 1,939 patients (Fig. 1).

\section{Measures}

Predictor Variables. We selected primary language and income as potential predictors of medication intensification. We identified primary language as either English or Spanish based on the language in which the patient elected to complete the survey. Annual household income was determined from a questionnaire item that classified participants into four categories, $<\$ 15,000, \$ 15,000-$

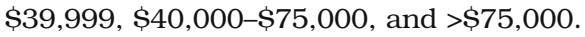

Anti-glycemic Medication Regimen Intensification. We used pharmacy claims data to classify patients with $A 1 c \geq 8 \%$ into two mutually exclusive categories based on their baseline medication regimens: 1) no anti-glycemic medications or 2) 
oral anti-glycemic medications only. We defined baseline for each patient as the date in 2000 or 2001 on which the elevated Alc was drawn. We classified patients as taking an oral antiglycemic medication at baseline if their pharmacy claims indicated prior fills for one or more of these medications that overlapped the date of the Alc test. As an example, a patient who last filled a prescription for a once daily oral anti-glycemic medication 60 days before the Alc was drawn and received a supply of 90 days would be classified as taking an oral antiglycemic medication. However, another patient who last filled a prescription for the same medication 120 days before the Alc was tested and also received a supply of 90 days would not be classified as taking that medication. We divided the oral antiglycemic medications into five subclasses: acarbose (acarbose, miglitol), sulfonylureas (glipizide, glyburide, micronized glyburide, chlorpropamide, glimepiride, tolazamide), metformin, thiazolidinediones (pioglitazone, rosiglitazone), and other (repaglinide, nateglinide). Patients could be taking medications from multiple different subclasses at baseline.

Based on a published algorithm applied to our pharmacy claims data, we defined two different potential measures of medication intensification at the 18 -month time point of follow-up. ${ }^{13}$ Patients were intensified by either 1) the addition of an anti-glycemic medication subclass by follow-up compared to baseline (any of the five oral medication subclasses or insulin) or 2) an increase in the dose of any existing oral anti-glycemic medication compared to baseline. For example, patients who were taking a medication from one subclass at baseline and medications from two subclasses at follow-up would be classified as having been intensified. As switches from one medication subclass to another (e.g. metformin to glyburide) were likely initiated due to side effects, potential medication interactions, or reasons other than an attempt to intensify therapy, we did not include such changes in our definition of medication intensification.

To calculate changes in oral anti-glycemic medication dosage over time, we created a composite variable measuring "dose intensity units," defined as [(quantity/days' supply) * dose strength] for the most recent fill before the Alc test and the most recent fill before the calendar date exactly 18 months later. Using data from the study cohort, we determined the minimum and maximum values of this variable for each specific medication, including values from baseline as well as follow-up in the calculation. We then divided the sample into quintiles based on the difference between the minimum and maximum values. For example, if the minimum dose intensity for metformin in the sample was (quantity of 60 tablets / 30 days' supply * $500 \mathrm{mg}$ strength) $=1000$ units, and the maximum dose intensity was (quantity of 120 tablets / 30 days' supply * $1000 \mathrm{mg}$ strength $)=4000$ units, the difference between minimum and maximum values would be 3000 units. The sample would be divided into quintiles of 3000 units / 5, or 600 units. Patients who moved from a lower quintile at baseline to a higher quintile at follow-up were classified as having their dose intensified. Patients who remained in the same quintile or moved to a lower quintile were not classified as having their dose intensified. We considered multiple medication strengths filled on the same day (e.g., metformin $850 \mathrm{mg}$ and $500 \mathrm{mg}$ ) as part of the same prescription.

Covariates. We used several survey-based covariates, including age, gender, duration of diabetes, and education (did not graduate high school, high school graduate, some college). On the basis of self-identification, patients were characterized as white, non-Latino; African American, nonLatino; Latino; Asian/Pacific Islander; or other. ${ }^{16} \mathrm{We}$ also included three covariates drawn from the medical record: the baseline Alc value, the type of diabetes treatment (oral medications or no medications) and the Charlson comorbidity score. The Charlson score is a commonly used measure of the severity of comorbid conditions, which has been shown to predict one-year mortality in cohort studies. ${ }^{17,18}$

\section{Statistical Methods}

We examined univariate distributions of all included variables, to assess for potential miscoded values and to ensure that variables included in continuous form approximated a normal distribution. We then determined the distributions of different anti-glycemic medication regimens at baseline (no medications or oral medications) by primary language and by annual income categories. We used a multivariate logistic regression model to examine adjusted differences in the frequency of intensified medication regimens at follow-up for patients with Alc $\geq 8 \%$ at baseline. We included all covariates in this model simultaneously, rather than adding them in a stepwise approach. In a second model, we added an interaction term for race/ethnicity*annual income, to measure whether any differences in intensification by income were influenced by patient race/ethnicity. Because we did not have information on drug benefit caps, which were common for managed Medicare recipients during the time period of the study, we also separately analyzed data limited to patients less than 65 years of age. Finally, as the plans in the study had different organizational structures that may have influenced intensification rates (i.e., integrated delivery systems vs. networkmodel systems), the models included a fixed effect to control for health plan.

Analyses were conducted using the SAS statistical package 9.2 (Cary, NC). We used the Hosmer-Lemeshow test to confirm goodness of fit. In order to ensure that the results were not distorted by high collinearity between different measures of socioeconomic status, we examined variance inflation factors (VIFs). All VIFs were less than 3.0, indicating that there was no significant multicollinearity.

\section{RESULTS}

Spanish speakers $(n=64)$ made up $3.3 \%$ of the sample, while the remainder was English-speakers ( $n=1,875$, Table 1). Approximately $28 \%$ of the sample $(n=551)$ had annual incomes < $\$ 15,000$ and $\$ 39,999$, while $32 \%(n=610)$ had annual incomes between $\$ 15,000$ and $\$ 40,000,25 \%(n=481)$ had annual incomes between $\$ 40,000$ and $\$ 75,000$, and $15 \%(n=297)$ had annual incomes over $\$ 75,000$ (Table 2).

Examining the sample characteristics at baseline, there were marked differences in education within ethnicity and income groups $(\mathrm{p}<0.001)$. Spanish-speaking patients $(69 \%)$ and patients with annual incomes $<\$ 15,000$ (50\%) were the least likely to have graduated high school (Tables 1 and 2). 
Table 1. Baseline Characteristics and Unadjusted Percentages of an Intensified Medication Regimen at Follow-Up by Primary Language, for Participants with Hemoglobin Alc $\geq 8 \%$

\begin{tabular}{|c|c|c|c|}
\hline & $\begin{array}{l}\text { Spanish- } \\
\text { speaking } \\
\text { patients } \\
(n=64)\end{array}$ & $\begin{array}{l}\text { English- } \\
\text { speaking } \\
\text { patients } \\
(n=1,875)\end{array}$ & $P$ value \\
\hline \multicolumn{4}{|l|}{ Baseline characteristics } \\
\hline Age in years (SD) & $60.7(12.9)$ & $58.7(12.1)$ & 0.20 \\
\hline Female sex (\%) & 53.1 & 51.9 & 0.85 \\
\hline Race/ethnicity & & & $<0.001$ \\
\hline White, non-Latino (\%) & 0 & 35.0 & \\
\hline Latino (\%) & 100 & 18.1 & \\
\hline $\begin{array}{l}\text { African American, } \\
\text { non-Latino (\%) }\end{array}$ & 0 & 15.5 & \\
\hline Asian/Pacific Islander (\%) & 0 & 21.0 & \\
\hline Other races/ethnicities (\%) & 0 & 10.5 & \\
\hline Annual income & & & $<0.001$ \\
\hline$<\$ 15,000(\%)$ & 50.0 & 27.7 & \\
\hline$\$ 15,000$ - \$39,999 (\%) & 42.2 & 31.1 & \\
\hline$\$ 40,000-\$ 74,999(\%)$ & 6.3 & 25.4 & \\
\hline >\$75,000 (\%) & 1.6 & 15.8 & \\
\hline Education & & & $<0.001$ \\
\hline$<$ High school (\%) & 68.8 & 21.2 & \\
\hline High school graduate (\%) & 15.6 & 31.3 & \\
\hline Some college (\%) & 15.6 & 47.5 & \\
\hline BMI & & & 0.21 \\
\hline$<25(\%)$ & 21.9 & 14.0 & \\
\hline $25-29(\%)$ & 26.6 & 29.3 & \\
\hline$>=30(\%)$ & 51.6 & 56.6 & \\
\hline $\begin{array}{l}\text { Duration of diabetes } \\
\text { in years (SD) }\end{array}$ & $10.5(7.1)$ & $10.8(9.3)$ & 0.80 \\
\hline $\begin{array}{l}\text { Charlson comorbidity } \\
\text { score (SD) }\end{array}$ & $1.75(1.1)$ & 2.19 (1.5) & 0.02 \\
\hline \multicolumn{4}{|l|}{ Type of diabetes treatment } \\
\hline Diet controlled (\%) & 31.3 & 28.8 & 0.66 \\
\hline Oral medications only (\%) & & & 0.53 \\
\hline Metformin only (\%) & 13.6 & 11.6 & \\
\hline Thiazolidinedione only (\%) & 0 & 1.7 & \\
\hline Sulfonylurea only (\%) & 52.3 & 42.5 & \\
\hline Acarbose only (\%) & 0 & 0.2 & \\
\hline$\geq 2$ oral medications (\%) & 34.1 & 43.9 & \\
\hline Baseline Alc value (SD) & $10.1(1.6)$ & $9.6(1.5)$ & 0.01 \\
\hline
\end{tabular}

Fisher's test used for statistical comparisons of race/ethnicity and oral medication/s used; chi-square test used for all other statistical comparisons

Statistically significant results shown in bold

Spanish-speaking patients had a higher mean baseline Alc (10.1\%) than English-speaking patients (9.6\%, p=0.01). However, no differences in baseline Alc by income were observed $(\mathrm{p}=0.49)$.

Overall, $42.4 \%$ of patients were taking intensified regimens at follow-up. In the multivariate analysis including all patients with diabetes and $\mathrm{Alc} \geq 8 \%$ at baseline, we did not find a statistically significant difference in the odds of taking an intensified medication regimen for Spanish speakers compared to English speakers (Table 3). However, we observed an increase in the odds of taking an intensified medication regimen among higher income patients. Compared to patients with annual incomes $<\$ 15,000$, patients with incomes of \$15,000-\$39,999 (OR 1.43, 1.07-1.92), \$40,000-\$74,999 (OR $1.62,1.16-2.26)$ or $>\$ 75,000$ (OR $2.22,1.53-3.24$ ) had increased odds of intensification. Higher baseline Alc values were also associated with increased odds of intensification, with an OR of 1.14 for each 1 percent increase in Alc. In a second model, the interaction term for race/ethnicity*income was not statistically significant $(p=0.29)$, indicating that the positive association between income and odds of intensification was consistent within different racial groups (data not shown).

The results of our two sensitivity analyses, namely including all patients with $\mathrm{Alc} \geq 7.0 \%$ at baseline and separately limiting the sample to patients less than 65 years of age, were similar to the results of our main analyses.

\section{DISCUSSION}

Contrary to one of our hypotheses, we did not find differences in the odds of taking an intensified medication regimen at follow-up for English speakers and Spanish speakers with $\mathrm{Alc} \geq 8 \%$ at baseline. However, we did find that among patients with suboptimal glycemic control, higher patient income was associated with an increase in the odds of intensification at follow-up. These results differ from a prior TRIAD analysis that found a difference of 3 percentage points in intensification rates between patients with annual incomes $<\$ 15,000$ versus $>\$ 75,000 .{ }^{13}$ That study limited the analytic sample to patients who completed a 2-year follow-up survey. The current study had nearly twice the sample size of the previous study and a much larger proportion of low income participants. As shown in a supplementary online appendix comparing results of the two studies (Supplementary Online Appendix), the current analysis found that the likelihood of intensification was 13 percentage points higher among patients with annual incomes of $>\$ 75,000$ compared to those with annual incomes $<\$ 15,000$. The marked difference in results between two studies from the same dataset underlines the importance of 1) clearly identifying the preferred analytic sample to test a given hypothesis, and 2) considering how the application of exclusion criteria will affect this sample.

There are several potential explanations for the association between income and intensification seen in the current study. Providers may hold unconscious stereotypes about lowincome patients, and/or be less likely to engage in patientcentered communication with low-income patients. ${ }^{19-21}$ These or other factors may dissuade providers from discussing an intensified medication regimen with low-income diabetic patients. Alternatively, because low-income patients tend to express more frequent concerns, symptoms, and psychosocial stressors compared to higher-income patients, less time may be available to discuss chronic disease management. ${ }^{19,22-24}$ A recent study of observed visits for diabetic patients in poor control found that each additional concern raised by the patient was associated with a $50 \%$ lower likelihood of a change in antiglycemic medication. ${ }^{25}$ Cost is often an important issue when medications are newly prescribed, and low-income patients are less able to afford copayments for additional medication/s beyond their existing regimen. ${ }^{26-28}$

Prior work using TRIAD data has shown that intensification is associated with an average decrease in Alc of $0.49 \%$ among patients with poor glycemic control. ${ }^{13}$ Furthermore, this effect was primarily observed among patients with 
Table 2. Baseline Characteristics and Unadjusted Percentages of an Intensified Medication Regimen at Follow-Up by Annual Income, for Participants with Hemoglobin Alc $\geq 8 \%$

\begin{tabular}{|c|c|c|c|c|c|}
\hline & $\begin{array}{l}\text { Income }<\$ 15,000 \\
(n=551)\end{array}$ & $\begin{array}{l}\text { Income } \$ 15,000-\$ 39,999 \\
(n=610)\end{array}$ & $\begin{array}{l}\text { Income } \$ 40,000-\$ 74,999 \\
(n=481)\end{array}$ & $\begin{array}{l}\text { Income }>\$ 75,000 \\
(n=297)\end{array}$ & $P$ value \\
\hline \multicolumn{6}{|l|}{ Baseline characteristics } \\
\hline Age in years (SD) & $63.5(12.1)$ & $59.1(12.4)$ & $55.1(11.1)$ & $54.9(9.9)$ & $<0.001$ \\
\hline Female sex (\%) & 67.9 & 53.9 & 40.5 & 36.7 & $<0.001$ \\
\hline Race/ethnicity & & & & & $<0.001$ \\
\hline White, non-Latino (\%) & 27.0 & 28.1 & 26.7 & 18.3 & \\
\hline Latino (\%) & 31.0 & 42.4 & 19.4 & 7.2 & \\
\hline African American, non-Latino (\%) & 50.9 & 23.3 & 16.5 & 9.3 & \\
\hline Asian/Pacific Islander (\%) & 16.4 & 33.7 & 29.2 & 20.7 & \\
\hline Other races/ethnicities (\%) & 23.4 & 27.3 & 31.1 & 18.2 & \\
\hline Spanish as primary language (\%) & 5.8 & 4.4 & 0.8 & 0.3 & $<0.001$ \\
\hline Education & & & & & $<0.001$ \\
\hline$<$ High school (\%) & 50.1 & 19.3 & 7.9 & 3.4 & \\
\hline High school graduate (\%) & 32.7 & 36.7 & 27.0 & 21.2 & \\
\hline Some college $(\%)$ & 17.2 & 43.9 & 65.1 & 75.5 & \\
\hline BMI & & & & & 0.17 \\
\hline$<25(\%)$ & 16.2 & 15.6 & 11.4 & 12.8 & \\
\hline $25-29(\%)$ & 26.5 & 30.7 & 31.2 & 28.3 & \\
\hline$>=30(\%)$ & 57.4 & 53.4 & 57.4 & 58.9 & \\
\hline Duration of diabetes in years (SD) & $12.7(10.5)$ & $11.3(9.1)$ & $9.1(7.7)$ & $9.3(8.4)$ & $<0.001$ \\
\hline Charlson comorbidity score (SD) & $2.4(1.8)$ & $2.2(1.5)$ & $2.0(1.2)$ & $1.9(1.1)$ & $<0.001$ \\
\hline \multicolumn{6}{|l|}{ Type of diabetes treatment } \\
\hline Diet controlled (\%) & 30.1 & 31.0 & 27.9 & 23.4 & 0.11 \\
\hline Oral medications only & & & & & 0.21 \\
\hline Metformin only (\%) & 13.4 & 8.8 & 12.1 & 12.8 & \\
\hline Thiazolidinedione only (\%) & 0.8 & 1.7 & 2.0 & 2.6 & \\
\hline Sulfonylurea only (\%) & 44.4 & 46.3 & 39.8 & 38.3 & \\
\hline Acarbose only (\%) & 0.3 & 0.5 & 0 & 0 & \\
\hline$\geq 2$ oral medications $(\%)$ & 40.8 & 42.8 & 46.1 & 46.3 & \\
\hline Baseline A1c value (SD) & $9.7(1.7)$ & $9.6(1.5)$ & $9.7(1.5)$ & $9.6(1.4)$ & 0.49 \\
\hline
\end{tabular}

Fisher's test used for statistical comparisons of race/ethnicity and oral medication/s used; chi-square test used for all other statistical comparisons Statistically significant results shown in bold

Table 3. Adjusted Odds of Taking an Intensified Regimen of AntiGlycemic Medications at Follow-Up, Among Participants with Hemoglobin Alc $\geq 8 \%$ at Baseline

\begin{tabular}{|c|c|c|}
\hline & Odds Ratio $(95 \% \mathrm{Cl})$ & $P$ value \\
\hline \multicolumn{3}{|l|}{ Primary language } \\
\hline English & 1.0 & \\
\hline Spanish & $1.60(0.91-2.82)$ & 0.11 \\
\hline \multicolumn{3}{|l|}{ Annual income } \\
\hline$<\$ 15,000$ & 1.0 & \\
\hline$\$ 15,000-\$ 39,999$ & $1.43(1.07-1.92)$ & 0.02 \\
\hline$\$ 40,000-\$ 74,999$ & $1.62(1.16-2.26)$ & 0.01 \\
\hline$>\$ 75,000$ & $2.22(1.53-3.24)$ & $<0.001$ \\
\hline \multicolumn{3}{|l|}{ Race/ethnicity } \\
\hline White, non-Latino & 1.0 & \\
\hline Latino & $0.87(0.62-1.21)$ & 0.39 \\
\hline African American, non-Latino & $0.75(0.54-1.04)$ & 0.09 \\
\hline Asian/Pacific Islander & $0.78(0.57-1.08)$ & 0.14 \\
\hline Other & $1.05(0.73-1.50)$ & 0.80 \\
\hline Age (per 1 year) & 0.997 (0.99-1.007) & 0.56 \\
\hline \multicolumn{3}{|l|}{ Sex } \\
\hline Male & 1.0 & \\
\hline Female & $0.95(0.78-1.15)$ & 0.60 \\
\hline \multicolumn{3}{|l|}{ Education } \\
\hline$<$ High school & 1.0 & \\
\hline High school graduate & $1.19(0.90-1.58)$ & 0.23 \\
\hline Some college & $1.19(0.89-1.60)$ & 0.24 \\
\hline Duration of diabetes (per 1 year) & $1.004(0.993-1.02)$ & 0.47 \\
\hline Baseline Alc (per 1\% change) & $1.14(1.07-1.21)$ & $<0.001$ \\
\hline Charlson comorbidity score & $1.01(0.95-1.09)$ & 0.68 \\
\hline
\end{tabular}

Adjusted for health plan

Statistically significant results shown in bold incomes $<\$ 15,000 .{ }^{15}$ Together with the findings in the current study, this suggests that the specific low-income patients who benefit the most from intensification are the least likely to actually be intensified.

To our knowledge, this is the first study comparing intensification of anti-glycemic medication regimens among English-speaking and Spanish-speaking patients with suboptimal glycemic control. Our study included relatively few Spanish speakers. However, examination of the observed confidence intervals suggests that markedly lower odds of intensification for Spanish speakers as compared to English speakers are unlikely, and the importance of any such differences on language-based variation in glycemic control are probably minimal. Using the approach published by Smith and Bates to extrapolate from our observed confidence intervals for the primary language variable, ${ }^{29}$ we estimate that the likelihood of the "true" OR for intensification among Spanish speakers being less than that for English speakers is approximately 5\%. Further, the likelihood of the "true" OR for Spanish speakers being $<0.75$ as compared to English speakers is less than $1 \%$. In other words, our results suggest that differences in factors other than medication intensification are the most likely explanations of poor glycemic control among Spanish speakers in managed care.

One explanation for the absence of an association between intensification and primary language, as well as the absence of differences in earlier analyses examining other processes of care, ${ }^{4}$ may be that managed care plans providing compre- 
hensive care to large Latino populations invest in high-quality interpreter services despite the lack of reimbursement from third-party payers. ${ }^{30}$ Providers who speak Spanish are also more likely to work in managed care settings and care for patients with private insurance than to care for Medicaid or uninsured patients. $^{31}$

Our study has several strengths, including its longitudinal design, large, randomly sampled cohort, and the inclusion of participants from 10 separate health plans. However, there are also limitations. First, we were unable to measure patient adherence to their anti-glycemic medication regimens, which may have resulted in some misclassification of intensification status if patients missed refills for the entire baseline or follow-up study window. Second, we did not analyze continuous claims data between baseline and follow-up and may have missed some patients for whom medication regimens were successfully intensified but subsequently deintensified before the follow-up measurement. Third, we were unable to measure intensification with behavioral strategies or overthe-counter herbal therapies. Finally, we could not measure the impact of intensification on long-term outcomes such as diabetes complications.

In summary, we found that low-income patients with suboptimal glycemic control are less likely to be on an intensified regimen of anti-glycemic medications at follow-up compared to higher-income patients. However, we did not find differences in medication intensification between Spanish speakers and English speakers in poor control, suggesting that other factors may be responsible for persistent language-based disparities in glycemic control. Future studies are needed to explain the reduced rate of intensification among low-income patients in managed care settings.

ACKNOWLEDGEMENTS: This study was jointly funded by Program Announcement number 04005 from the Centers for Disease Control and Prevention (Division of Diabetes Translation) and the National Institute of Diabetes and Digestive and Kidney Diseases. The findings and conclusions in this report are those of the authors and do not necessarily represent the views of the funding organizations.

Significant contributions to this study were made by members of the Translating Research into Action for Diabetes (TRIAD) Study Group. The authors in particular acknowledge Robert Gerzoff, MS for his extensive statistical and programming assistance. The authors also acknowledge the participation of our health plan partners.

Dr. Duru and Dr. Rodriguez received support from the Network for Multicultural Research on Health and Healthcare, funded by the Robert Wood Johnson Foundation.

Dr. Mangione received support from the Resource Centers for Minority Aging Research/Center for Health Improvement of Minority Elderly (RCMAR/CHIME) funded by the NIH/NIA (P3O AG021684), and the UCLA Older Americans Independence Center funded by the NIH/NIA (5 P30 AG028748).

Dr. Mangione and Dr. Rodriguez received support from the Drew/ UCLA Project EXPORT Center funded by the NIH/NCMHHD (P2O MDOOO182).

\section{Conflicts of Interest: None disclosed.}

Open Access: This article is distributed under the terms of the Creative Commons Attribution Noncommercial License which permits any noncommercial use, distribution, and reproduction in any medium, provided the original author(s) and source are credited.
Corresponding Author: O. Kenrik Duru, MD, MS; Division of General Internal Medicine/Health Services Research, David Geffen School of Medicine, University of California, Los Angeles, 911 Broxton Plaza, Los Angeles, CA 90095, USA (e-mail: kduru@ mednet.ucla.edu).

\section{REFERENCES}

1. Saaddine JB, Cadwell B, Gregg EW, et al. Improvements in diabetes processes of care and intermediate outcomes: United States, 1988-2002. Ann Intern Med. 2006;144:465-74.

2. Cheng EM, Chen A, Cunningham w. Primary language and receipt of recommended health care among Hispanics in the United States. J Gen Intern Med. 2007;22(Suppl 2):283-8.

3. Mainous AG 3rd, Diaz VA, Saxena S, Geesey ME. Heterogeneity in management of diabetes mellitus among Latino ethnic subgroups in the United States. J Am Board Fam Med. 2007;20:598-605.

4. Brown AF, Brown AF, Gerzoff RB, et al. Health behaviors and quality of care among Latinos with diabetes in managed care. Am J Public Health. 2003;93:1694-8.

5. Brown AF, Gregg EW, Stevens MR, et al. Race, ethnicity, socioeconomic position, and quality of care for adults with diabetes enrolled in managed care: the Translating Research Into Action for Diabetes (TRIAD) study. Diab Care. 2005;28:2864-70.

6. Mainous AG 3rd, Majeed A, Koopman RJ, et al. Acculturation and diabetes among Hispanics: evidence from the 1999-2002 National Health and Nutrition Examination Survey. Public Health Rep. 2006;121:60-6.

7. Chaturvedi N, Jarrett J, Shipley MJ, Fuller JH. Socioeconomic gradient in morbidity and mortality in people with diabetes: cohort study findings from the Whitehall Study and the WHO Multinational Study of Vascular Disease in Diabetes. BMJ. 1998;316:100-5.

8. Phillips LS, Branch WT, Cook CB, et al. Clinical inertia. Ann Intern Med. 2001;135:825-34.

9. Derose KP, Baker DW. Limited English proficiency and Latinos' use of physician services. Med Care Res Rev. 2000;57:76-91.

10. Campos C. Addressing cultural barriers to the successful use of insulin in Hispanics with type 2 diabetes. South Med J. 2007;100:812-20.

11. Thackeray R, Merrill RM, Neiger BL. Disparities in diabetes management practice between racial and ethnic groups in the United States. Diabetes Educ. 2004;30:665-75.

12. Goldman DP, Joyce GF, Zheng Y. Prescription drug cost sharing: associations with medication and medical utilization and spending and health. JAMA. 2007;298:61-9.

13. McEwen LN, Bilik D, Johnson SL, et al. Predictors and impact of intensification of antihyperglycemic therapy in type 2 diabetes: Translating Research Into Action for Diabetes (TRIAD). Diab Care. 2009;32:971-6.

14. The Translating Research Into Action for Diabetes (TRIAD) study: a multicenter study of diabetes in managed care. Diab Care. 2002;25:386-89

15. Frankel L. Improving data quality in a sample survey. Marketing Science Institute. 1983:1-11.

16. US Census Bureau. Racial and ethnic classifications used in Census 2000 and beyond. Available at www.census.gov. Accessed November 9, 2010.

17. Charlson ME, Pompei P, Ales KL, Mackenzie CR. A new method of classifying prognostic comorbidity in longitudinal studies: development and validation. J Chron Dis. 1987;40:373-83.

18. Martins M, Blaise R. Evaluation of comorbidity indices for inpatient prediction models. J Clin Epidemiol. 2006;59:665-9.

19. Fiscella K, Epstein RM. So much to do, so little time: care for the socially disadvantaged and the 15-minute visit. Arch Intern Med. 2008; 168:1843-52.

20. van Ryn M, Burke J. The effect of patient race and socio-economic status on physicians' perceptions of patients. Soc Sci Med. 2000;50:813-28.

21. Fiscella K, Goodwin MA, Stange KC. Does patient educational level affect office visits to family physicians? J Natl Med Assoc. 2002;94:157-65.

22. Bierman AS, Lawrence WF, Haffer SC, Clancy CM. Functional health outcomes as a measure of health care quality for Medicare beneficiaries. Health Serv Res. 2001;36:90-109.

23. Fiscella K, Franks P. Does psychological distress contribute to racial and socioeconomic disparities in mortality? Soc Sci Med. 1997;45:1805-9.

24. Blumenthal D, Causino N, Chang YC, et al. The duration of ambulatory visits to physicians. J Fam Pract. 1999;48:264-71. 
25. Parchman ML, Pugh JA, Romero RL, Bowers KW. Competing demands or clinical inertia: the case of elevated glycosylated hemoglobin. Ann Fam Med. 2007;5:196-201.

26. Briesacher BA, Gurwitz JH, Soumerai SB. Patients at-risk for costrelated medication nonadherence: a review of the literature. $\mathrm{J}$ Gen Intern Med. 2005;11:864-71.

27. Piette JD, Heisler M, Horne R, Alexander GC. A conceptually based approach to understanding chronically ill patients' responses to medication cost pressures. Soc Sci Med. 2006;62:846-57.

28. Tseng CW, Tierney EF, Gerzoff RB, et al. Race/ethnicity and economic differences in cost-related medication underuse among insured adults with diabetes: the Translating Research Into Action for Diabetes Study. Diab Care. 2008;31:261-6.

29. Smith AH, Bates MH. Confidence limit analyses should replace power calculations in the interpretation of epidemiologic studies. Epidemiology. 1992;3:449-542.

30. Ku L, Flores G. Pay now or pay later: providing interpreter services in health care. Health Aff Millwood. 2005;24:435-44.

31. Yoon J, Grumbach $\mathbf{K}$, Bindman AB. Access to Spanish-speaking physicians in California: supply, insurance, or both. J Am Board Fam Pract. 2004; 17:165-72. 